\title{
Quality Management System in Drug Industry: A Review
}

\author{
Priyambada Pandey*1 and Goyal Anju² \\ ${ }^{1}$ M. Pharma Research Scholar, B.N. Institute of Pharmaceutical Sciences, India \\ ${ }^{2}$ Professor \& HOD, Department of Pharmaceutical Quality Assurance, BN Institute of Pharmaceutical Sciences, India
}

Received: January 04, 2018; Published: January 11, 2018

*Corresponding author: Priyambada Pandey, M. Pharma Research Scholar, B.N. Institute of Pharmaceutical Sciences, Udaipur, India, Tel: 7073250880;

Email: priyambadapandey93@gmail.com

\begin{abstract}
Quality of medicines means meeting the required specifications. Quality management in pharmaceutical industries, is an important subject because the drugs / or pharmaceutical products are directly delivered to the customers body system, thus identity, purity safety and ultimately appropriate quality of product are strongly essential. ICH Guidelines are established with a view to bring uniformity in the products worldwide. It helps in export and import of drug products worldwide. Maintaining quality in the products is a complex process and needs to take into account various guidelines like GMP, GLP and many more. There is a Quality assurance department in all the Pharma industries whose job is to look if all the required guidelines are being followed in the industries or not. Quality auditing is the process through which they check internally or externally and ensure everything is running right. The present paper focuses on the Quality management system in the Drug industry and their elements.
\end{abstract}

Keywords: Quality Assurance; Quality Management system; GMP; GLP; Drug Industry

\section{Introduction}

In the present scenario the context of Quality has emerged as an important factor. People are wise enough to choose things that assure to fulfill their demands. If we precisely define Quality it means meeting the specifications that are summarized keeping in mind the demand of today's fast changing world. If we talk of Pharmaceutical Industry, quality becomes an unavoidable thing. Quality management in pharmaceutical industries, is an important subject because the drugs / or pharmaceutical products are directly delivered to the customers body system, thus identity, purity safety and ultimately appropriate quality of product are strongly essential. There are numerous guidelines worldwide that has made some sort of rules and specifications which must be followed by every pharmaceutical industry. To maintain quality in pharmaceutical products, Quality Management System is followed. Internationally harmonized guidance ICH Q10 governs the concept of current pharmaceutical quality management system for Registration of Pharmaceuticals for Human Use and USFDA and in final phases [1].

\section{Quality Management System (QMS)}

Quality management is defined as the aspect of management function that determines and implements the "quality policy", i.e. the overall intention and direction of an organization regarding quality, as formally expressed and authorized by top management.

\section{The basic elements of quality management are:}

a) An appropriate infrastructure or "quality system", encompassing the organizational structure, procedures, processes and resources

b) Systematic actions necessary to ensure that a product (or service) will satisfy given requirements for quality. The totality of these actions is termed "quality assurance [2,3] (Figure 1).

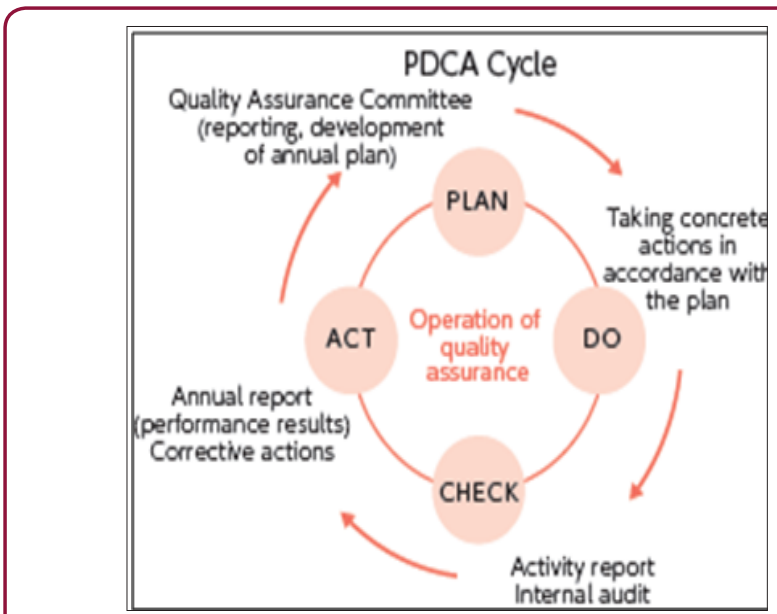

Figure 1: PDCA Cycle. 
The Top Ten Responsibilities of the Pharmaceutical Quality Unit [4]
a) To establish the quality system
b) To audit compliance to the quality system
c) To establish procedures and specifications
d) To establish manufacturing controls
e) To perform laboratory tests or examinations
f) To review and approve or reject all things cGMP
g) To ensure investigation of non conformance
h) To keep management informed
i) To describe responsibilities in writing
j) To remain independent

\section{Elements of Quality Management System [5]}

\section{A quality management system typically consists of four} facets

a) Quality planning: Process of translating quality policy into processes, procedures, and instructions to achieve measurable objectives and requirements

b) Quality assurance: Planned and methodical activities executed as part of a quality system to provide confidence that process, product, or service requirements for quality are being satisfied

c) Quality control: Act of monitoring, appraising, and correcting a process, product, or service to ensure requirements for quality are being satisfied

d) Quality improvement: Process of analyzing performance and taking methodical, systemic actions to improve it

\section{International Conference on Harmonization [6,7]}

ICH is a joint initiative involving both Regulators and Researchbased industry initiatives of the Europe, Japan and US for the scientific and technical discussions of the testing procedures; required to assess and ensure the Safety, Quality and Efficacy of the medicines. ICH stands for "International Conference on Harmonization" of Technical Requirements for Registration of Pharmaceuticals for Human use.

\section{ICH Q10}

ICH Q10 describes one comprehensive model for an effective pharmaceutical quality system that is based on International Organization for Standardization (ISO). Quality concepts, includes applicable good manufacturing practice (GMP) regulations, and complements. Implementation of ICH Q10 throughout the product lifecycle should facilitate innovation and continual improvement and strengthen the link between pharmaceutical development and manufacturing activities.
Aim

ICH was established in 1990, as a joint regulatory/ industry project to improve, through harmonization, the efficiency of the process, for developing and registering new medicinal products in Europe, Japan and US.

\section{Purpose of ICH}

The basic purpose of ICH are

a) To monitor, update and increase the international harmonization of Technical Requirements.

b) To ensure Safety, Efficacy and Quality of medicines that must be developed and registered in the most efficient and cost effective manner.

c) To promote and protect public health from an international perspective.

d) To prevent unnecessary duplication of clinical trials in humans.

e) To minimize the use of animal testing without compromising the safety and effectiveness.

f) To improve the efficiency of Global Drug Development.

\section{Need of ICH}

The guideline helped in achieving harmonization in the quality of products worldwide for the export of medicines without any interruption on the world level.

\section{Quality Management System in Testing Laboratories [8- 10]}

Professionals of testing laboratories have shown increasing interest in understanding the QMS and attaining accreditation status for their services since the introduction of international standards for the quality management system (QMS). Thus Quality assurance therefore is defined as the process or the end of the process which confirms for the integrity of a product to meet the standard for the intended use. Quality assurance is an obligation automatically imposed on the manufacturer of any product to ensure that it meets the needs of the end-user in the measures intended for use. For the end-user, the benchmark of quality is perfection they cannot allow less than $100 \%$.

\section{Elements of the Quality Management System}

The laboratory is a complex system, involving many steps of activity and many people. The complexity of the system requires that many processes and procedures be performed properly. Therefore, the QMS model, which looks at the entire system, is very important for achieving good laboratory performance. The QMS is defined as a 'management system to direct and control an organization with regard to quality. The QMS covers the laboratory activities, including drug sampling, analysis and reporting. The QMS consists of documentation of the laboratory policy and objectives, system procedures and instructions for assuring the quality of its 
results to meet safety and regulatory requirements and to satisfy the needs of the customers.

\section{Pharmaceutical Quality Management System [11]}

It is applicable to drug products, including biotechnology and biological products, throughout the product lifecycle the systems supporting the development and manufacture of pharmaceutical drug substances. It includes:

\section{Pharmaceutical Development}

a) Manufacturing and development of APIs.

b) Manufacture of medical kits and devices for investigation.

c) Development of medical delivery systems.

d) Pilot plant scale-up activities

e) Manufacturing process of formulation

f) Development of medical devises for accurate dosing

\section{Analytical Method Development}

\section{During Manufacturing Process}
a) Acquisition and control of materials
b) Provision of facilities, utilities, and equipment
c) Production (including packaging and labelling)
d) Quality control and assurance
e) Release
f) Storage

\section{During Product Technology Transfer}

\section{During product discontinuation}

a) Retention of sample and related documentation

b) Continued product assessment and reporting

\section{Conclusion}

The term quality cannot be confined to one definition. It is tensile in nature and people define it in their own ways but one thing is common in all and that is satisfaction. Manufacturer is satisfied if the product meets it specification and consumer is happy when the particular product fulfils his need. But in anyways Quality is unavoidable thing today and one cannot ignore it. When it comes in context of Pharma then Quality is a legal issue and must be maintained in pharmaceutical products. The present paper focuses on some aspects and need of maintaining Quality in Pharma through Quality Management System

\section{References}

1. Dubey Ne, Gupta H, Sharma RK, Dubey Ni, Dubey N (2011) Pharmaceutical Quality Management System: Current Concept. Journal of Advanced Pharmacy Education \& Research 2: 120-124.

2. Quality assurance of pharmaceuticals: A compendium of guidelines and related materials 2, 2nd updated edition, Good manufacturing practices and inspection.

3. Lakhal L, Pasin F, Liman, M (2006) Quality management practices and their impact on performance. Int J Qua. Rel. Mgmt 23(6): 625-646.

4. (2009) Q10 Pharmaceutical Quality System, U.S. Department of Health and Human Services Food and Drug Administration Centre for Drug Evaluation and Research (CDER) Centre for Biologics Evaluation and Research p. 2-19.

5. CFR - Code of Federal Regulations, Title 21 "Food and drugs" Chapter I" Food and drug administration" sub chapter C "Drugs-General" Part 211 "Current Good Manufacturing Practice For Finished Pharmaceuticals" .

6. Mario Chen (2007) Brief Introduction to the ICH Guidelines. Family Health International Biostatistics Workshop, New Delhi, India.

7. (2015) ICH guideline Q10 on pharmaceutical quality system EMA/ $\mathrm{CHMP} / \mathrm{ICH} / 214732 / 2007$.

8. ISO 17025: 2005. General requirements for the competence of testing and calibration laboratories.

9. ISO 9000: 2000. Quality management systems- Fundamental and vocabulary.

10. Jadaun GPS, Kasana H, Saklani V, Jain R, Singh S (2015) Quality Management System in Testing Laboratories JPQA 1(1): 53-56.

11. Lachman L, Hanna SA, Lin K (1976) Quality control and assurance. The Theory and Practice of Industrial Pharmacy. 2nd Edn, Varghese Publishing House, Bombay, India, pp. 804-855.

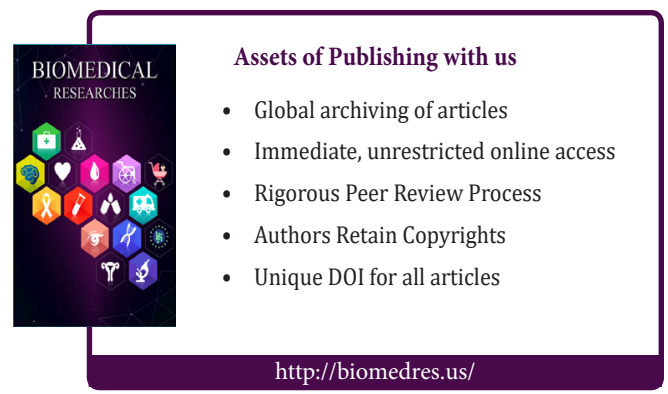

